\title{
ntorno das identificações
}

\author{
Prof ${ }^{a}$. Dr $\stackrel{a}{ }$. Mayra Rodrigues Gomes
}

\begin{abstract}
Resumo: Este artigo mostra resultados parciais advindos de uma pesquisa mais ampla. Procura relatar observações comparativas entre os seguintes jornais televisivos: Jornal Nacional, Jornal da Record e Jornal da Cultura. Tais observaçōes foram realizadas sobre uma coleta, gravação em vídeo, das emissões destes veículos durante a primeira semana de março de 2004 . Este é o período em que se destaca o polêmico caso Waldomiro Diniz, que mobilizou a opinião pública e políticos de todos os partidos em torno de CPIs e MPs. Nossas considerações, comparações e valorizaçōes, foram feitas a partir dos modos de abordagem deste assunto por cada um dos veículos mencionados.
\end{abstract}

\section{Palavras-chave: diversidade; fontes; vozes}

\begin{abstract}
This paper shows partial results taken from an ample research. It tries to bring a comparative analysis between the following television news programs: Jornal Nacional, Jornal da Record and Jornal da Cultura. The analysis was accomplished over data, recorded in video, securing these media emissions along the first week of march, 2004. This period is marked by the polemic Waldomiro Diniz case, an issue of impropriety in a institutional position. Our notes, implying values, are made upon de way these news programs choose to present the case.
\end{abstract}

\section{Key words: diversity; source; voices}

1

Professora Doutora do Departamento de Jornalismo e Editoração da Escola de Comunicações e Artes, USP, onde ministra as disciplinas Ciências da Linguagem e Ética. É autora de Jornalismo e Ciências da Linguagem, São Paulo, Edusp e Hacker Editores, 2000; Repetição e Diferenças nas Reflexões sobre Comunicação. São Paulo, Annablume, 2001; Ética e Jornalismo. São Paulo, Escrituras, 2002; Poder no Jornalismo. São Paulo, Edusp e Hacker Editores, 2003.
A simpatia, inclinação que reúne pessoas, é uma das formas com as quais nos referimos às identificações. Quando falamos sobre nossas preferências por alguém ou alguma coisa, anunciadas em termos de nossas simpatias, desenhamos muito mais que rebarbas ou linhas opcionais acessórias à nossa "personalidade". Desenhamos um quadro de nossa estruturação individual porque, ainda que apareçam como fragmento, nossas inclinaçōes se compōem num todo coerente, partes que se encaixam com precisão. No que concerne a preferências não há aleatoriedade, ou sequer um jogo a pairar, leve e solto, sobre as circunstâncias. Nelas testemunhamos encontros com elementos de um modelo que nos alimenta, elementos que compõem o que desejamos ser, nosso ideal de eu, lugar do que imaginamos ser ou vir a ser. 
Assim posto, toda vez que fazemos o elogio de alguma coisa este é, desde sempre, o elogio de nós mesmos, questão bastante complicada quando se trata de emitir um parecer valorativo sobre qualquer campo da atividade humana mantendo a pretensão a um mínimo de isenção ou equidade.

Ora, as pesquisas servem a nos livrar, ainda que parcialmente, desta aporia: enunciamos nossos sonhos, na forma da afirmação ou da negação, agora com o respaldo de dados, dados que comprovam uma ocorrência. É certo que a ocorrência diz respeito a viabilidades, fundamento possível de nosso viés, passando ao largo da legitimidade. Mas, embora como fabulação, saímos ilesos.

Pois bem, temos uma pesquisa, de longa data, que no momento atual se desenvolve pela comparação entre veículos. Embora seu objetivo não seja mostrar a superioridade de um veículo sobre outro, foi inevitável constatar a melhor qualidade, do ponto de vista de nossos ideais, delineada pelo Jornal da Cultura, fato que será nosso assunto neste texto.

Para demonstrar a pertinência da afirmação anterior, tomaremos, como ponto de partida, a freqüência temática, a freqüência e variação das fontes, porque seu número se relaciona tanto à meta de apuração dos fatos quanto à meta de diversidade de opiniões. Nosso período de coleta e observação compreende edições do Jornal Nacional, do Jornal da Record e do Jornal da Cultura durante a primeira semana de março de 2004. Esta semana é precedida pela eclosão do escândalo Waldomiro Diniz que mobilizou a opinião pública e políticos de uma ou outra posição. $\bigcirc$ tratamento dado por cada um dos veículos será nosso foco de atenção.

\section{Quadriculado e quadrículo}

Nossa pesquisa supõe a tarefa do jornalismo, da mesma forma a de outros campos, como a da composição de um quadriculado do espaço público. Tal idéia é aplicação de conceitos formulados por Michel Foucault, para quem o quadriculamento do espaço é uma operação corrente. Visa o dimensionamento em partes que se estruturam na formação de um todo mas que, estando bem delineadas, permitem uma operação de vigilância e controle, a criação de mecanismos de contenção e administração do espaço assim circunscrito.

Em nossos estudos sobre jornalismo, essa divisão espacial (espaço simbólico) compreende quadrículos, categorizados tematicamente, que permitem a formação de dispositivos disciplinares (conceituados por Michel Foucault) e a atualização de palavras de ordem (conceituadas por Gilles Deleuze). É sobre a instalação destes vetores que a comunicação, entendida como calcada na repetição, permite-se o desenvolvimento de uma estratégia mestra: a redundância enquanto freqüência.

Neste momento, trabalhamos com os modos de inserção dos veículos estudados a partir de um quadriculado obtido sobre a repetição de temas. Foi assim que, comparando inserções chegamos às conclusões que gostaríamos de apresentar.

Ao tomarmos os dados numa triagem simples, obtivemos a seguinte representatividade temática: 
JORNAL NACIONAL

Total de matérias $=\mathbf{1 3 0}$

ACIDENTES/CATÁSTROFES: 11

ATOS DE GUERRA: 2

ATOS DO GOVERNO: 20

ATOS/MANIFESTAÇÕES PELOS DIREITOS HUMANOS: 4

AUTOREFERENCIALIDADE: 3

CRIMINALIDADE/VIOLÊNCIA: 31

ECONOMIA: 11

ESPORTES: 7

ESTATÍSTICAS/BEM ESTAR/REPORTAGENS: 11

MODOS DE VIDA: 2

NOTÍCIAS EVENTOS/CULTURA/CIÊNCIA/PERSONAGENS DE DESTAQUE: 12

OPINIÕES SOBRE PROJETOS E EFEITOS: 9

POLÍTICA: 7

\section{JORNAL DA RECORD}

Total de matérias $=\mathbf{1 1 7}$

ACIDENTES/CATÁSTROFES: 1.

ATOS DE GUERRA: 5.

ATOS DO GOVERNO: 21.

ATOS/MANIFESTAÇÕES PELOS DIREITOS HUMANOS: 7

CRIMINALIDADE/VIOLÊNCIA: 35.

ECONOMIA: 11.

ESPORTES: 8.

ESTATÍSTICAS/BEM ESTAR/REPORTAGENS: 11.

NOTÍCIAS EVENTOS: CULTURA/CIÊNCIA/PERSONAGENS DE DESTAQUE: 5.

OPINIÕES SOBRE PROJETOS E EFEITOS: 1.

POLÍTICA: 12.

\section{JORNAL DA CULTURA}

Total de matérias $=108$

ACIDENTES/CATÁSTROFES: 4.

ATOS DO GOVERNO: 19.

ATOS DE GUERRA: 2.

ATOS/MANIFESTAÇÕES PELOS DIREITOS HUMANOS: 6.

AUTOREFERENCIALIDADE: 5.

CRIMINALIDADE/VIOLÊNCIA: 15.

ECONOMIA: 6.

ESPORTES: 2.

ESTATÍSTICAS/BEM ESTAR: 8.

NOTÍCIAS EVENTOS/CULTURA/CIÊNCIA/PERSONAGENS DE DESTAQUE: 15.

OPINIÕES SOBRE PROJETOS E EFEITOS: 16.

POLÍTICA: 10.

Começamos por isolar, dentre as matérias classificadas tematicamente como atos do governo, aquelas voltadas para o caso Waldomiro. Levamos em conta somente as explicitamente delineadas na perspectiva deste, porque há cruzamentos genéricos. Foi aí que notamos a primeira distinção das posições. 
Dentre as 20 matérias que o Jornal Nacional dedica ao governo, 10 estão relacionadas ao caso Waldomiro, 2 veiculadas em quinto bloco de notícias, 4 em quarto, 2 em terceiro e 2 em primeiro. Notemos que o caso está em primeiro plano, somente na terça feira. Das 21 matérias que o Jornal da Record veiculou sobre o governo, 15 estão diretamente relacionadas ao caso, 10 em segundo bloco, 4 no primeiro bloco do dia $1^{\underline{a}}$ de março e 1 no terceiro do mesmo dia. Entre as 19 matérias que o Jornal da Cultura dedicou ao tema 14 relacionam-se ao caso Waldomiro, 1 em quinto bloco, 1 em terceiro bloco, 2 em segundo e 10 distribuídas pelos primeiros blocos de todos os dias da semana.

Certamente esse quadro denota a atenção dedicada ao caso, por parte do Jornal da Cultura, dando-nos a certeza de que os eventos foram bastante esmiuçados, fato que nos deixa com a possibilidade de uma profundidade maior, pela exposição de diversos ângulos da questão.

Ressalta-se o fato, nada desprezível, de que, enquanto os outros dois veículos se voltavam para a cobertura dos eventos relacionados ao caso Waldomiro, o Jornal Nacional procurou concentrar suas matérias, em relação ao tema atos do governo, nas propostas governamentais ligadas ao incentivo à construção civil e à dotação de verba para a recuperação de rodovias e ferrovias. Em cima deste último assunto, até desenvolveu uma extensa reportagem sobre a importância das vias de locomoção para o escoamento e exportação dos diversificados produtos brasileiros. Esta ocorrência chega a causar estranhamento, diante dos rumos seguidos pelos outros veículos, e passa a representar uma tentativa de desvio da atenção.

Em contrapartida, o Jornal da Cultura trouxe uma reportagem, com direito ao depoimento de várias personagens implicadas, sobre a origem da fita incriminadora que foi parar na redação da revista Época. A narração dos fatos coube ao repórter Andrei Meirelles que encabeçou a matéria da Época. Segundo ele, o senador Antero Paes de Barros, relator da CPI dos bancos dos Estados, costuma receber denúncias. A fita foi parar em suas mãos e ele não reconheceu as pessoas envolvidas. Acostumado a passar informações para o repórter Andrei Meirelles, entregou-lhe a fita dizendo que parecia haver corrupção ali, mas não sabia de que teor. $O$ repórter identificou as pessoas e levou a fita a perito da Unicamp para averiguar sua autenticidade. Somente três dias depois o senador foi informado de que Waldomiro Diniz tentava acordos com o bicheiro Carlinhos Cachoeira. Só esta reportagem envolveu o testemunho e a opinião de diversas pessoas, inclusive a dos âncoras do Jornal da Cultura, o que detona uma abertura para diversas fontes.

\section{Vozes}

Quanto às fontes, na forma da presença de vozes diferenciadas, podemos explorá-las sob diferentes ângulos. Primeiramente consideraremos o quadro de incidências que constatamos em relação ao tópico Opiniões sobre projetos e efeitos. Este abarca as matérias voltadas para entrevistas, por elas constituídas, e em que a opinião de alguém é claramente buscada.

O Jornal Nacional, de um total de 130 matérias, dedica 9, de maneira exclusiva, a entrevistas; o Jornal da Record, de um total de 117 dedica, com exclusividade, somente 1; o Jornal da Cultura, de um conjunto de 108, dedica 16 e sai, portanto, ganhando em incidência. Ainda que a cifra pareça desprezível, devemos considerar que, entre estas 16 ocorrências, encontra-se a presença de 
um entrevistado, a cada dia da semana, que veio com o objetivo de explicitar facetas e enfoques possíveis para o caso Waldomiro e suas reverberações.

Assim, na segunda-feira, Heródoto falou com o deputado do PT, Cândido Vaccarezza, que é a favor da regulamentação dos bingos, regulamentação que eliminaria a questão da lavagem de dinheiro. Na terça-feira, Heródoto entrevistou Luiz Fernando Delazari que dá testemunho de ligação do bingo com a máfia italiana e com a lavagem de dinheiro. Este é a favor da cessação das atividades e aprova a MP da proibição dos bingos. Na quarta-feira, Heródoto entrevistou o senador Jorge Bornhausen. Este afirmou que a polícia não teve a agilidade necessária e reforça a necessidade de uma CPI. Na quinta-feira, foi veiculada entrevista com o jornalista Cláudio Tognolli, especialista em sigilos e vazamentos. Este manifestou a opinião de que há um exagerado uso do segredo na justiça brasileira. Na sexta-feira, Heródoto entrevistou o senador Eduardo Suplicy. Este se diz a favor da CPI para esclarecer o caso e até inocentar José Dirceu. Lembrou que Lula prometia que qualquer um dos seus ministros compareceria para esclarecimentos, que é o que tem acontecido, e também deveria aplicar-se a Dirceu.

Esta amostra é suficiente para expor um desenho constituído por diversas posições políticas e, conseqüentemente, diversos enfoques para o caso explorado. A ela somam-se as notações de pesquisas de opinião pública, outra forma de explorarmos a diversidade de vozes.

É nestes termos que o Jornal da Record menciona a pesquisa DataFolha, para mostrar que a maioria dos eleitores, $81 \%$, defende a CPI de Waldomiro Diniz e o Jornal da Cultura indica pesquisa do Ibope, pela qual se revela que $68 \%$ dos brasileiros concordam que se divulguem informações dos processos.

Claro que as matérias voltadas para entrevistas e pesquisas de opinião não encerram a questão, pois todas as outras são pontilhadas por entrevistas na forma de pequenos depoimentos, em que políticos e pessoas do povo se manifestam. Prosseguimos na direção dos tipos cuja opinião é procurada e aqui nos deparamos com o fato de que tanto o Jornal da Record quanto o Jornal da Cultura abriram espaço onde compareceram testemunhos dos mais variados setores: da situação e da oposição, dos envolvidos com empresas lotéricas e dos envolvidos com as personagens centrais ao caso, enquanto o Jornal Nacional concentrou-se nos depoimentos de figuras do governo, dando assim maior ênfase às argumentações advindas do lugar que estava sendo posto em xeque.

Essa explícita tomada de posição do Jornal Nacional é reforçada pela ausência de comentários críticos por parte de seus âncoras. Em nome da justeza, esta posição diz respeito a todos os envolvidos, acusados e acusadores. Se num primeiro momento podemos pensá-la como isenção, tal isenção se vê neutralizada, uma vez que anteriormente se deu reforço à posição do governo. Ou seja, há uma opinião manifesta pelo veículo através do procedimento da escolha das vozes que ele permite falarem; há uma opinião expressa na forma da omissão.

Onde há matérias pontuadas por comentário dos âncoras, é preciso fazer distinções quanto à sua natureza. O Jornal da Record, na figura de Boris Casoy, pratica uma constante vigilância sobre a ordem e por ela clama abertamente. Sobretudo, faz a cobrança da palavra dada pelos políticos, no passado, confronta-a com suas atitudes atuais. A freqüente formulação "Isto é uma vergonha” pontifica, reclama e exemplifica o modo de comentar. Já o Jornal da Cultura procura mostrar os diversos ângulos problemáticos da questão, para os quais os âncoras apontam sempre que oportuno. Heródoto, particularmente, volta e meia comenta por meio de comparação entre 
ocorrências, passadas e atuais. Mas, não aí julgamento de mérito da palavra dada, ao menos na forma explícita da cobrança.

Acreditamos que, na procura da diversidade e manifestação de opinião que estamos acompanhando, é necessário incluir o papel das charges. Até nelas há abordagens diferenciadas que marcam a possibilidade, pela crítica ou neutralidade, da apresentação de enfoques.

O Jornal da Record não veicula charges. As charges de Chico Caruso, Jornal Nacional, reforçam a idéia, durante o período por nós observado, de que o governo tem um grande abacaxi nas mãos. Presidente e alto escalão são mostrados carregando abacaxis a usando-os como capacete. Brincam com as vantagens econômicas de que Waldomiro usufrui, sem menção a sua ligação com o governo, ou melhor, sua posição nele.

Enquanto isto, Pegolli, chargista do Jornal da Cultura, faz uma crítica corrosiva aos políticos do governo e suas atitudes face ao escândalo Waldomiro. Temos charge parodiando a entrega do Oscar em que políticos recebem prêmios em categorias negativas; noutra, Lula comparece cantando com Gil "Haiti é aqui..." ; em telefonema a Bush, Lula afirma que no Brasil não se quer descobrir nada; na seqüência, os políticos do governo aparecem discutindo soluções, cômicas, para abafar CPI.

Em charges, a posição amena sinaliza uma anuência; certamente a posição crítica, para além da opinião manifesta, alude a enfoques diferenciados.

Com os dados apresentados, se não é notória a empatia com o Jornal da Cultura, certamente é digno de nota o sonho que nos impele: de que o jornalismo possa responder ao compromisso com a informação pela via da diversidade de enfoques, de vozes a serem ouvidas, condição de democracia.

\section{Referências bibliográficas}

DELEUZE, Gilles. Conversações. São Paulo: Editora 34, 1998.

1986

. Différence et répétition. Paris: Presses Universitaires de France,

DELEUZE, Gilles e GUATTARI, Felix. Mil platôs. Capitalismo e esquizofrenia. Vol. 1. Rio de Janeiro: Editora 34, 1995a.

DELEUZE, Gilles e GUATTARI, Felix. Mil platôs. Capitalismo e esquizofrenia. Vol. 2. Rio de Janeiro: Editora 34, $1995 \mathrm{~b}$.

FOUCAULT, Michel. A vontade de saber. História da sexualidade vol. I. Rio de Janeiro: Edições Graal, 1997.

. Microfísica do poder. Rio de Janeiro: Edições Graal, 2001.

. Vigiar e punir. Petrópolis: Editora Vozes, 1999. 